\title{
Otomycosis Treatment: Topical Drops versus Cream - A Prospective Randomized Study
}

\author{
Prasun Mishra*, Sheenu Sachdeva, Maitri Kaushik and Deeksha Aggrawal \\ Department of ENT Bharati Vidyapeeth Medical College, India
}

Submission: September 04, 2017; Published: September 14, 2017

*Corresponding author: Prasun Mishra, Department of ENT Bharati Vidyapeeth Medical College, Pune, India, Tel: +91 020 40555555; Extn: 277; Fax: 24371116; Email : majorprasun@yahoo.co.in

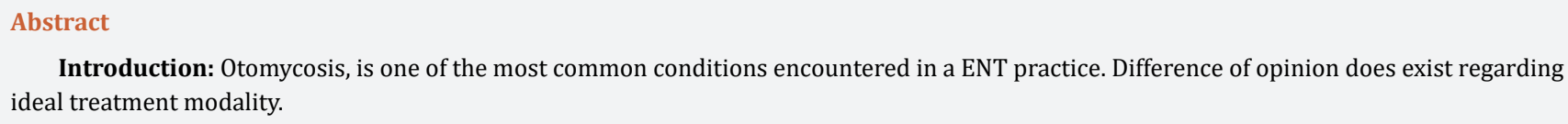

Introduction: Otomycosis, is one of the most common conditions encountered in a ENT practice. Difference of opinion does exist regarding ideal treatment modality.

Aim: Compare the treatment efficacy of $1 \%$ Clotrimazole drops with $1 \%$ Clotrimazole Cream in management of otomycosis.

Method: Randomized control study was performed over 3 months. 60 patients, clinically diagnosed with otomycosis were included in study. Patients were randomly allotted to treatment arms of either $1 \%$ clotirmazole drops or $1 \%$ clotirimazole cream. Improvement in symptoms of pain, pruritis and blocked sensation on one and two weeks follow up was recorded. External auditory canal was evaluated for improvement in otomycotic debris. All patients were asked the opinion about preferred modality of treatment.

Results: When compared to the symptoms on day one at day 07 , the change in symptoms in both the groups was significant ( $<<0.05)$. Significant difference was also noted for the improvement in otomycotic debris in both the groups. The group with cream had significantly more blocked sensation. On second week follow up, significant improvement was noted for all the symptoms and otomycotic debris. 45 out of 60 patients preferred using cream.

Conclusion: $1 \%$ topical clotrimazole and cream are equally effective in management of otomycosis.

Keywords: Otomycosis; $1 \%$ clotirmazole; Cream; Drops

\section{Introduction}

Otomycosis, also known as fungal otitis externa is one of the most common conditions encountered in a general ENT practice. Wide spread use of steroid and antibiotic drops or prior otologic procedures have led to increase in prevalence of this condition $[1,2]$. Prevalence of this condition is more in tropical and subtropical humid climates. A high prevelance rate of $9 \%$ has been mentioned for otomycois amongst patients presenting with otitis externa [3]. The common organism that cause otomycosis are Aspergillus fumigatus, Aspergillus Aspergillus niger, Candida albicans of which Aspergillus Niger is found to be predominant $[4,5]$. Though this condition is not fatal it does presents a challenge for otolaryngologists for it often needs long-term treatment and follow-up. It also tends to recurr quiet often [6].

Difference of opinion does exists regarding ideal treatment modality of otomycosis. Treatment options for otomycosis commonly include elimination of predisposing factor, thorough cleaning of the canal, use of topical antifungals. Studies show clotrimazole as one of the most effective agents for management of Otomycosis, with reported efficacy rate of $95 \%$ to $100 \%$. It is available as powder, lotion, and solution and is considered free of ototoxic effects [7]. Commonly topical Clotrimazole drops are used 2- 3 times a day for 7-10 days or till cure. Putting drops so frequently for long is definitely cumbersome especially for office class patients. Some studies have suggested use of Clotrimazole cream for this purpose however there is a dearth of comparative randomized data. Thus in this study the aim was to compare the treatment efficacy of $1 \%$ Clotrimazole drops with $1 \%$ Clotrimazole Cream.

\section{Methods}

This was randomized control study performed over a period of 3 months. Inclusion criteria consisted of all consenting patients with otomycosis. Patients with chronic otitis media, mastoidectomy cavity, uncontrolled diabetes and those using hearing aids were excluded from study. Diagnosis of otomycosis was based on clinical feature and otoscopy finding of matted hyphae, spores, or curdy precipitate in the external auditory canal. Patients were told to rate the symptoms as per visual analogue scale (VAS). The symptoms were pain, blocked sensation and pruritis. A proper suction clearance of the external canal was done by otoendoscopy or otomicroscopy. Using computer 


\section{Global Journal of Otolaryngology}

generated random number table patients were allotted to either of the two groups. Group A consisted of 1\% Clotrimazole drops and group B comprised of 1\% Clotrimazole cream.

Group A patients were instructed to instill 1\% Clotrimazole drops three drops three times a day and to review in opd after a week. For group B patients, 1\% Clotrimazole cream was filled in $2 \mathrm{ml}$ syringe and external auditory canal was filled with this cream under endoscopic guidance. Cotton was placed in EAC and patient was told to review in outpatient department after a week. During follow up the symptoms were evaluated again and EAC was examined. Patient was considered treated when there was no evidence of residual fungal debris. If during the first visit patient had evidence of otomycosis, the treatment was repeated and patient reviewed again after a week. After cure all the patients were asked a standard question. "If the results are same will they prefer one time instillation of cream or topical drops which needs to be instilled daily three times". The answer was noted.

\section{Statistics}

Requisite statistical tests were applied on the results. Fishers's Exact Test was used for comparing the symptom change between two groups. McNemar's test was used for Intra group symptom improvement. $\mathrm{P}$ value $<0.05$ was considered as significant difference.

Results

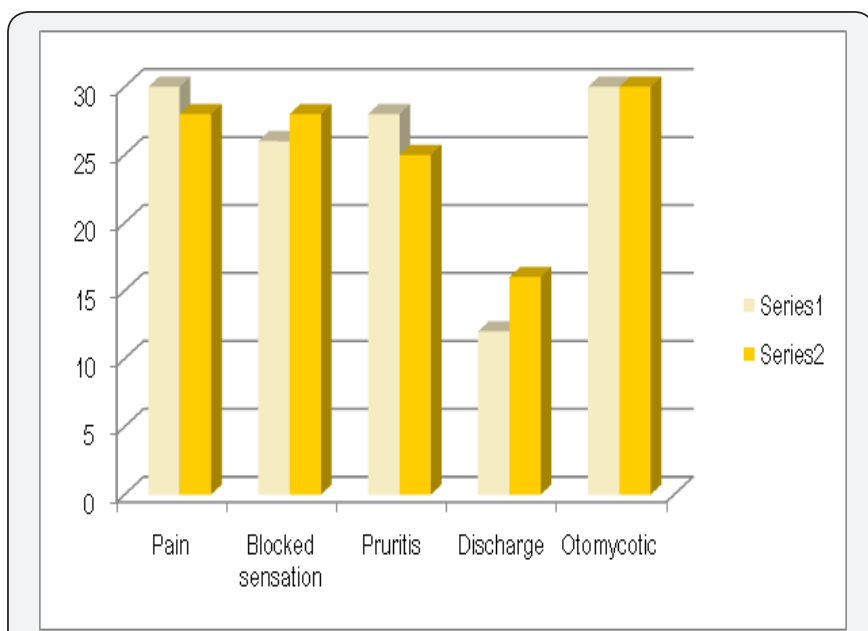

Figure 1: Symptoms in both the group at start of treatment.

Total 60 patients formed the study group with 30 in each group. Gender wise distribution in both the group was almost equal. In both the group all the patients were evaluated after seven days and the same symptoms were noted. External auditory canal of patient was checked with endoscope and findings recorded. The results at the end of a week are as per Figures $1 \& 2.11$ patients in the group with antifungal drops persisted with pain and 13 in the cream group. 8 patients in the drops groups had pruritis as compared to 6 in the cream group. 3 patients in drops group had discharge as compared to 4 in the cream group. Otomycotic debris persisted in 9 patients in the drops group and 11 patients in the cream group. 13 patients in the drop group persisted with complaints of ear blockage as compared to the cream group which had 22 patients having blocked ear sensation.

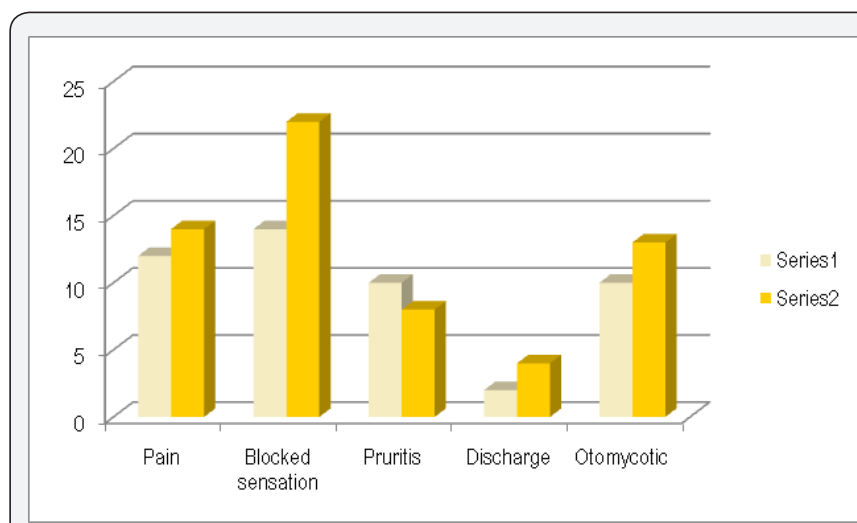

Figure 2: Symptomatic change and otomycosis remnant after 7 days.

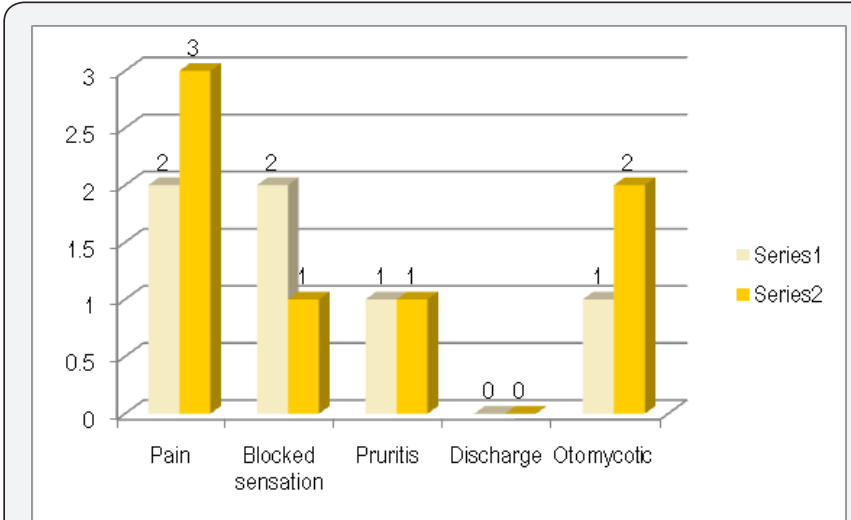

Figure 3: Symptomatic change and otomycosis remnant after 2 weeks

When compared to the symptoms on day one to day 07 the change in symptoms in both the groups was significant ( $\mathrm{p}<$ $0.05)$. Statistically significant difference was also noted for the improvement in otomycotic debris in both the groups. With inter group comparison there was no satistically significant difference in the symptomatic improvement between both the groups except for symptom of ear blockage. The group with cream had significantly more sensation of ear blockage compared to the drops group the results of change in symptoms after two weeks as per Figure 3. On second week follow up significant improvement was noted for all the symptoms when compared to symptoms on day one. There was no significant difference between the two groups in terms of symptoms and remnant otomycotic debris. For the response to the question asked to all the patients at the end regarding choosing the preferred modality of treatment (drops Vs cream) given that the efficacy was same, 45 out of 60 patients preferred using cream considering the convenience of treatment modality.

\section{Discussion}

Otomycosis is a common condition encountered in ENT Outpatient department which consists of fungal infection of 
the external auditory canal wall. The patient mainly presents with otalgia, pruritis, block sensation, and otoscopy shows presence of otoscopy finding of matted hyphae, spores, or curdy precipitate in the external auditory canal. Study by Pradhan et al. [6] suggested pruritis as the main symptom of otomycosis whereas study by Ho Tang et al. [7] reported it to be $23 \%[6,8]$. There is no proper agreement regarding the effect of various antifungal agents used for otomycosis and various agents have been used for the same [9]. Though, use of appropriate antifungal agent along with mechanical debridement remains the mainstay of treatment. Amongst antifungals topical clotrimazole remains widely used agent [7]. 1\% Clotrimazole cream has been used for treatment of this condition with good efficacy [10]. In present study too patients gave good response with use of cream.

Patients using 1\% clotrimazole drops have to instill drops in affected ear three to four times a day. This can become very cumbersome for office going person. Besides, direct instillation of antifungal solution is also associated with burning sensation especially in cases of perforated drum [11]. There is an argument that use of antifungal cream increases the contact time of the agent with the meatal skin. Blocked sensation was more in patients in whom topical cream was used which is a known fact as reported by Hurst et al. [12]. There are not many studies comparing the use of $1 \%$ clotrimazole drops with that of $1 \%$ cream in treatment of otomycosis.

Study by Abou Halawa et al. [11] used clotrimazole ointment for otomycosis and compared use of wick with regular application and found that self application and wick application both have same efficacy for relief from otomycosis [11]. Studies have reported that otomycosis recur in almost $8.89 \%$ of treated subjects [12]. It takes around 2-3 weeks of to achieve cure from disease. Thus to reduce chance of recurrence and to improve patient well being as well as considering the ease of installation the present study compared cream versus drops. The question asked to all patients at the end of treatment as to their preference of treatment modality went in favor of $1 \%$ clotrimaole cream. This may be due to the fact that patients prefers one time instilling of cream instead of self medication of putting drops 3-4 times a day.

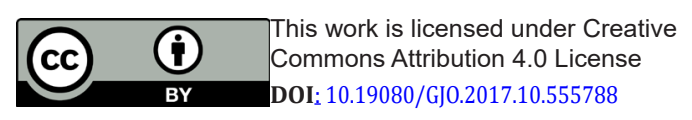

\section{Conclusion}

From this prospective randomized study it can be concluded that use of $1 \%$ topical clotrimazole drops and $1 \%$ clotrimazole cream are equally effective in management of otomycosis. Cream leads to more block sensation during the first seven days when compared to drops. However when given a choice considering the fact of only single time application, patients prefer use of topical cream over drops for treatment of otomycosis.

\section{References}

1. Chander J, Maini S, Subrahmanyan S (1996) Otomycosis a clinic mycological study and efficacy of mercuro chrome in its treatment. Mycopathologia 135: 9-12.

2. Ho T1, Vrabec JT, Yoo D, Coker NJ (2006) Otomycosis: clinical features and treatment implications. Otolaryngol Head Neck Surg 135(5): 787791.

3. Mugliston T, O Donoghue G (1985) Otomycosis: a continuing problem. J Laryngol Otol 99: 327-333.

4. Kaur R, Mittal N, Kakkar M, Aggarwal AK, Mathur MD et al. (2000) Otomycosis: a clinic mycologic study. Ear, Nose and Throat Journal 79(8): 606-609.

5. Hoshino T, Matsumoto M (2006) Otomycosis: Subdermal growth in calcified mass. Eur Arch Otorhinol aryngol 263: 875-878.

6. Ho T, Vrabec J, Yoo D (2006) Otomycosis: clinical features and treatment implications. Otolaryngology Head and Neck Surgery 135: 787-791.

7. Anwar K, Gohar MS (2014) Otomycosis: clinical features predisposing factors and treatment implications. Pakistan Journal of Medical Sciences 30(3): 564-567.

8. Pradhan B, Tuladhar NR, Amatya RM (2003) Prevalence of otomycosis in outpatient department of otolaryngology in Tribhuvan University Teaching Hospital Kathmandu Nepal. Ann Otol Rhinol Laryngol 112: $384-387$.

9. Stern JC, Shah MK, Lucente FE (1988) In vitro effectiveness of 13 agents in otomycosis and review of the literature. Laryngoscope 98: 1173-1177.

10. Ologe FE1, Nwabuisi C (2002) Treatment outcome of otomycosis in Ilorin Nigeria. West Afr J Med 21(1): 34-36.

11. S Abou halawa, MA Khan, AA AlRobaee, AA Alzolibani, HA AlShobaili, et al. (2012) Otomycosis with Perforated Tympanic Membrane: Self medication with Topical Antifungal Solution versus Medicated Ear Wick. Int J Health Sci Qassim 6(1): 73-77.

12. Hurst WB (2001) Outcome of 22 cases of perforated tympanic membrane caused by otomycosis. J Laryngol Otol 115: 879-880.

\section{Your next submission with Juniper Publishers} will reach you the below assets

- Quality Editorial service

- Swift Peer Review

- Reprints availability

- E-prints Service

- Manuscript Podcast for convenient understanding

- Global attainment for your research

- Manuscript accessibility in different formats

( Pdf, E-pub, Full Text, Audio)

- Unceasing customer service

Track the below URL for one-step submission https://juniperpublishers.com/online-submission.php 